\title{
The Durability of Immunity to SARS-COV-2 Infection in Man
}

\author{
Ibrahim M.S. Shnawa \\ Department of Biotechnology, College of Biotechnology, University of Qasim ,Babylon Iraq
}

\begin{abstract}
The durability of covid-19 immunity in man was being explored in this opinion. Criteria for determination of post-recovery protective immunity were suggested. Current published information indicated that it may last for three to six months in accordance with the sero-conversion and sero-prevalence actual studies. While according to memory B and T cell studies, it was demonstrated that both of memory B and memory $\mathrm{T}$ cells can be detected up to eight months in post recovery period of mild to critical cases of covid-19 and up to 12 months in a retrospective study on large scale seasonal circulating coronavirus human re- infection incidence .Though the extent to which post-recovery protective $\mathrm{B}$ and $\mathrm{T}$ cell immunity operate to re-infection still remain to elucidated. Factors affecting the duration of herd immunity to sars-cov-2 were suggested. basis.
\end{abstract}

Keywords: Covid-19, coronovirus durability ,memory cells, post-recovery ,protective, sero-conversion ,seroprevalence.

DOI: $10.7176 / \mathrm{JNSR} / 11-22-06$

Publication date: November $30^{\text {th }} 2020$

\section{Introduction}

The pathogenicity of sars-cov-2 virus in man can be attributed to the virus itself or to the indirect immunepathogenesis resulted from the immune responses or immune dys-regulation initiated by that responses[Vabret et al.2020].Sars-cov-2 virus infection in man induced an array of immunologic consequences that best explained by the marked inter-individual variation in severity, infection forms ,and pathology[Vabret et al.2020,,Jesenak et al.2020 ].There are six genetic variants[Illarionov \&Pivovarova 2020 ],six infection forms[Sudre et al.2020] and five duration types[ Branswell 2020].The nature of the post-infection immunity is rather different from that of post-vaccination immunity[ Speiser \&Bachmann 2020] Duration of the immune protection post to infection or post to vaccination means the time period between the presence of the effector immune outcomes in peripheral blood stream of the recovered patients and the incident of first natural or experimental re-infection[ Branswell 2020].While ,the efficacy indicate the ability of patient immune mechanisms to prevents the infection and its consequences in post-infection or post-vaccination time periods[ Speiser \&Bachmann 2020,Kirkaldy et al .2020].The principles of viral herd immunity is just like that of other microbial infections .Though ,the Sarscov-2 herd immunity seemed to be quite different, since the its excessive mortality ,threshold, and heterogeneity[Marias \& Sorrell 2020] The objective of the present opinion was to focus onto durability of immunity in recovered patients and in human herd immunity.

\section{Theme}

The theme upon which this opinion organized was that the immunity to covid-19 going to be tackled onto; i-herd member[individual] immunity level and ii- herd immunity level. The herd member level immunity was mapped into; nature of epitopes, nature of immune response ,immune tissue injuries and nature of the post-recovery immunity. Herd immunity level was reviewed and the eligible immune measures put-forwarded .The criteria for post-recovery immunity was suggested for individual and for herd so far.

\section{Herd member level[Branswell 2020]:}

3.1 Epitope Nature

Sars-cov-2 virus have an array of several epitopes,like;Th2 B cell dependent epitope like that of spike proteins[Liu et al.2020 ],Th1 T Cell dependent epitopes[ Altmann 2020],mucosal invariant T cell epitope [Parrot et al.2020] and auto-epitope [ Bastard et al.2020 ].

\subsection{Immune Responses}

The epitopes [II-1] may trigger; I - antibody B cell immune responses[Liu et al. 2020 ], ii-T cell immune response[Altmann 2020], iii-mucosal invariant T cell antiviral responses[Parrot et al.2020 ] and iv- Autoantibody responses as anti-cytokine[Bastard et al.2020 ].So far the immune response time curve is concerned,covid-19 patients have shown dipartite response nature[Stephens \&McElrath 2020] as;

a-Sero -conversion established within seven to ten days as IgM then class switched to $\operatorname{IgG}$ within three weeks after infection.

b-Sero-conversion established within 14 days as IgM then class switched to I $\mathrm{gG}$ within three weeks

IgM responses can assure current infection. While, IgG in absence of IgM may indicate clearance of the virus 
[ Stephens \&MacElrath 2020 ].Anti spike protein virus neutralizing antibody is correlated with immune protection as held by some workers[Addetetia et al.2020 ]. Auto immune responses to interferon family has been found causing life threatening pneumonia due to the effects of the interferon made the patient vulnerable to life threatening infections[ Bastard et al. 2020 ] Sars-cov-2 infection activate T cells in the first week of the infection and virus specific memory $\mathrm{T}$ cells of CD4+ T cells and to lesser extent CD8+ T cells. The T cell responses reported to peak within two weeks but remain detectable 100 days or more. On recovery sars-cov-2 specific memory CD4+ $\mathrm{T}$ cells in $100 \%$ and CD8+ T cell in about $70 \%$ of test convalescents[Stephens \&McElrath 2020 ].Mucosal invariant $\mathrm{T}$ cell responses in mild to moderate cases showed lowered numbers in peripheral blood but recruited to the respiratory airway niche then re-migrate and homed into the blood stream on recovery of the patients [ parrot et al.2020] .Current research have shown that both of memory B and memory $\mathrm{T}$ cells remained available in the blood stream in post recovery up to six to eight months in mild to severe covid-19 cases[ Sherina et al.2020,Zuo et al .2020].

\subsection{Immune Tissue Injuries}

There have been reported numbers of immune tissue injuries accompanied the immune responses during and/or post to sars-cov-2 infection or vaccination[ Speiser \& Bachmann 2020] such as; Cytokine storm[ Ragab et al. 2020],micro-thrombi [ McFadyen et al.2020 ],antibody disease enhancement, and T cell disease enhancement [Speiser \& Bachmann 2020].

\subsection{Post-infection Immunity Scenarios[Branswell 2020]: \\ 3.4.1 Built in Immunity}

There were several current supports to the idea of built in immunity operable in covid-19 as an antibodies with virus neutralizing ability specific to spike proteins in subjects whom not exposed to covid-19 disease[Ng et al. 202] and CD4 T cells and to lesser extent CD8 T cells in a subjects whom unexposed to Covid-19[Mateus et al. 20201,Sette \&Crotty 2020].These findings were explained on the bases of cross-immunity with other circulating seasonal coronaviruses. Such sort immunity may take part in reducing herd immunity threshold, reduced the severity of the infection course and enhance the efficacy of the vaccines[ $\mathrm{Ng}$ et al.2020,Mateus et al.2020 ]. 3.4.2 Sterilizing Immunity[Branswell 2020]:

It is a state of post-recovery immunity where the humeral ,cellular and their mediator mechanisms can render the recovered patients with long lived immunity to reinfection as state of measles. The current information indicted that the holdings of most covid-19 workers believe that it far from being operable in covid-19.

3.4.3 Funcitunal Immunity [Branswell 2020]:

It is a state of post- recovery immunity where the effector and/or the memory immune mechanisms of the recovered patient are operable on recall of reinfection insults. It seems this scenario is more fitting with the case of covid-19.

3.4.4 Waning Immunity [Branswell 2020]:

It is a state of post-recovery immunity where the overall immune mechanisms of the infected patients renders them immune till recovery then become declining in due course. Some workers holds that this scenario may be in operation in some of the patients.

3.4.5 Lost or Negative Immunity[Branswell 2020]:

It is a state of post-recovery immunity, where the net outcomes of the overall effector immune mechanisms of the recovered patients were used to evade the infection vajor , and when recovery was commenced there are no functional immune mechanisms at all. Patient upon re-infection be in a state just like that of first exposure.

3.4.5 Collective or Mix up Immunity[branswell 2020]:

Still there are workers whom holds the idea of mix up scenarios .e.g.Covid-19 herd immunity may sectored based on the assumed scenarios to more than one type of immunity scenarios .Some individuals were with functional, others with waning or lost. And a third with sterilizing for instance,Table-1. 
Table 1: Immunity of human to sars-co-2 infection, duration and possible efficacy in post recovery period*

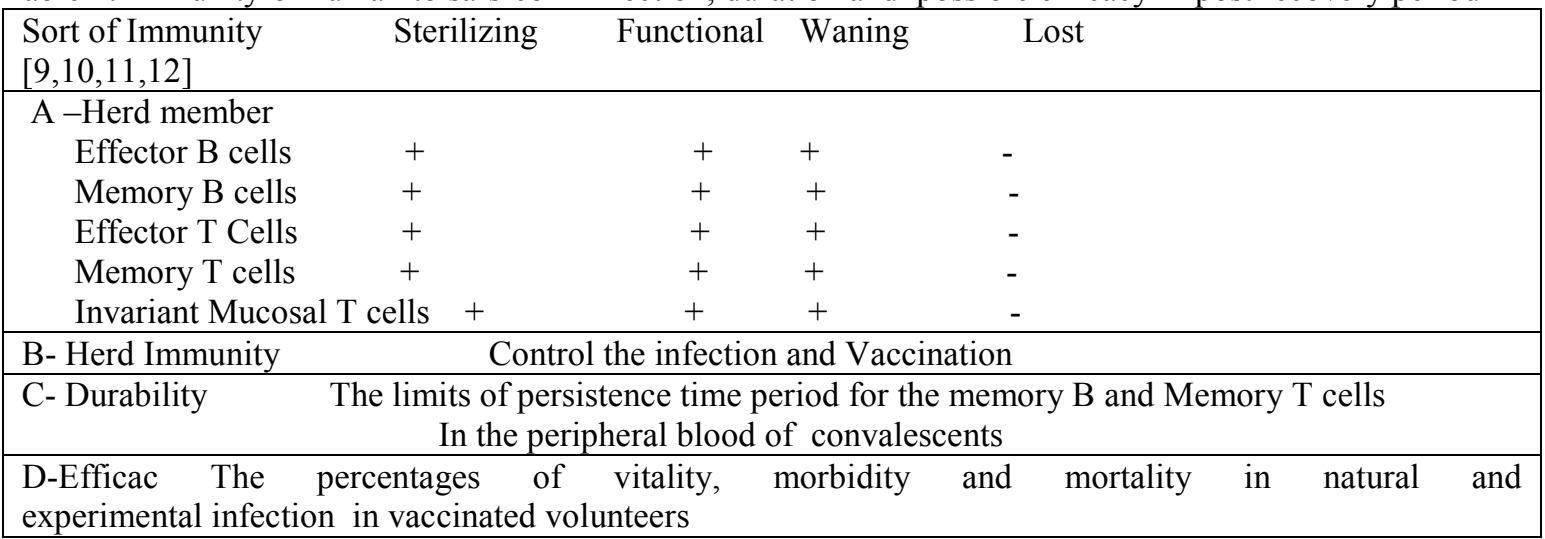

*Based on Branswell [2020].

\section{Herd Immune level:}

4.1 :Herd Immunity:

The herd is a group of individuals living in certain local environment ,the niche .Such individuals do affect each other and expresses mutual effect onto their niche. When an infectious insult contract this herd, there are three sorts of responses may be traced in this herd, The individual response and herd response as well as the herd effect. Herd immunity is a collective general term includes immune and none-immune factors. The immune factors are; past infection, past vaccination as well as the concurrent infections. The none-immune factors are genetic control by major histocompatibility complex, nutritional as well as sanitary measures. The herd immune response mapped into low, medium and high responders. The distribution of immune individuals within the herd obey the normal Gaussian distribution curve or it might be of skewd nature[Sette \& Crotty 2020 ]. To establish herd immunity to any infectious agent one have to follow either infection or vaccination immunity among the individuals forming the herd .If we seek sars-cov-2 virus infection in the case herd, there should several rounds of natural infection to affect the herd in order to establish an immune herd to this virus. This will cost millions of deaths of the patients. The vaccination choice till now not in hand. There some factor affecting the herd immune responses such as; built in immunity[Ng et al.2020,Mateus et al.2020, Sette \& Crotty 2020],reproduction number . limits of heterogeneity , and herd immunity threshold .Presence of built in immunity, herd immunity threshold and low heterogeneity of herd these all will reduce the herd immunity threshold .It seems that covid-19 herd immunity rather difficult to attain due to high reproduction number(2-3), marked heterogeneity , marked transmissibility , partial protectivity of the neutralizing antibodies induced by the experimental vaccines in none-human primates and in-availability of human licensed vaccine to date[ Shnawa 2014,Fontanet \&Cauchemez 2020, Sanchez 2020,Dmarco 2020,Lewis 2020 ]. The mathematical model[ Fontanet \& Cauchemez 2020] for calculation of the reproduction number on the assumption that the individuals forming the herd mix homogenously and are equally susceptible and contagious is as

$\mathrm{R}=(1-\mathrm{Pc})(1-\mathrm{P} 1) \mathrm{Ro} . . . . .($ question 1$)$

Where $\mathrm{Pc}$ is the relative reduction in transmission rates due to none-drug intervention,P1 is the proportion of the immune individuals and Ro is the reproduction number in the absence of control measures in fully susceptible population . Ro may vary across the herd over time depending on the nature and number of contacts among herd and potential environmental factors. In absence of control measures Pc equal to zero the condition for herd immunity( $R$ equal to less than one where

$\mathrm{R}=(1-\mathrm{P} 1)$ Ro ....... (question 2$)$ is therefore achieved when proportion of immune individuals reaches $\mathrm{P} 1=1-1 /$ Ro..............(question 3), Table 2. 
Table 2 : Ultimate herd immunity limits*

\begin{tabular}{|l|l|l|l|l|l|}
\hline $\begin{array}{l}\text { Virus } \\
\text { Infection } \\
\text { Spread }\end{array}$ & Ro & $\begin{array}{l}\text { Effective } \\
\text { Ro limits }\end{array}$ & Death \% & Measures & $\begin{array}{l}\text { Determinant of effective } \\
\text { herd immunity near 50- } \\
60 \%\end{array}$ \\
\hline Uncontrolled & $>2$ & $?$ & High & $\begin{array}{l}\text { Prolonged lock down short } \\
\text { term locked down, } \\
\text { overwhelmed health care }\end{array}$ & $\begin{array}{l}\text {-Un-controlled infection } \\
\text {-Controlled infection } \\
\text {-Vaccination } \\
\text { - all of the three }\end{array}$ \\
\hline Controlled & $1-2$ & Effective & $\begin{array}{l}\text { Within the } \\
\text { accepted } \\
\text { range to } \\
\text { low }\end{array}$ & $\begin{array}{l}\text {-on-off physical distancing } \\
\text {-on-off isolation } \\
\text {-targeted low risk group }\end{array}$ & As above \\
\hline $\begin{array}{l}\text { Controlled } \\
\text { Local } \\
\text { epidemic } \\
\text { spread } \\
\text { elimination }\end{array}$ & $<1$ & Effective & Low & $\begin{array}{l}\text {-Active Case testing } \\
\text {-Hyper-vigilance } \\
\text { extensive testing } \\
\text {-Active case finding } \\
\text {-Prolonged lockdown }\end{array}$ & As above \\
\hline
\end{tabular}

*Based on; Marias and Sorrell [2020].

\section{Durability:}

5. 1:Individual level;

The duration of an efficient immunity for human or zoonotic infections can be life- long immune protection or say for three years .Or less than one year as counted in months post infection or post vaccination .It is mainly dependent on the viability and function of memory B and T cells .By duration of immune efficacy we mean the time period between the presence of immune response outcomes and being effective in prevention of natural or experimental challenge with life infective virus. Immune durability in covid-19 convalescents can be judged by the following determinants;

- The time period for availability and efficacy of the anti-spike neutralizing antibodies in the post recovery patients[Wajnberg et al. 2020,Figueiredo-Campose et.al. 2020].

- The time period for the availability of effector and memory B cells in the peripheral blood of convalescent in post recovery patients[Wajinberg et al. 2020].

- The time period for the availability of the effector and memory $\mathrm{T}$ cells in the peripheral blood of convalescent in post recovery patients[Lebert et al. 2020].

- Retrospective studies for the seasonal coronavirus records for prolonged time period to map the period of reinfections post to recovery[Edridge et al. 2020].

- Detailed study to the records available for covid -19 re-infected patients.

The duration of neutralizing anti-spike antibodies were determined in actual field large scale studies were three months in one study[Wajnberg et al,2020] and six months in other study[Figueiredo-Campose 2020] and retrospective mapping to seasonal actual coronovirus re-infection initiation was evident to be 12 months[Edridge et al. 2020].The efficacy of such antibodies to prevention of re-infection still a matter of debate. Some workers holds the idea that neutralizing antibodies are protective[ Addetetia et al. 2020 ] others however does not holds such believe. Both of memory B and T cells lasts for up to six to eight months post recovery in mild to severe covid-19 cases [ Zuo et al.2020,Sherina et al.2020].

5.2:Herd level[ Sanchez 2020,Dmarco 2020,Lewis 2020,Fontanet \&Cauchemez 2020]:

The durability of human herd immunity to Sars-cov-2 infection largely determined by;

- Nature of the pathogen

- Strength of the Individual immune system function

- Percent of immune individuals within the herd

- Infection exposure limits and number of infection waves affecting the herd

- Availability and coverage extent of vaccination programs

- Presence of Pre-immunity or built-in immunity.

For sure the availability(duration) of ; virus neutralizing antibodies for three to 6 months and T cell subsets for up to three to eight months were taken as an overall of medium to large size population studies . Results below and above of these limits were not uncommon to be reported among individuals forming herds. But still the duration of immune protection among the herd is a matter of debate [ Zuo et al.2020, Sherins at al.2020]. 


\section{Concluding Remarks:}

There is no doubts about the nature of immunity to Sars-cov-2 virus human infection initiated humeral anti-spike neutralizing antibody, effector B cell, effector T cell ,memory B cell and memory $\mathrm{T}$ cell are the foundations of infection and re-infection recall immunity. Effector B and effector T cell important in the first exposure and during infection till recovery. Memory B and memory $\mathrm{T}$ cells supposed to be operable onward upon re-exposure or reinfection .Built-in immunity as a sort of humeral and cellular cross or shared immunity take part in reduction of disease severity, reduction of herd immunity threshold, and may enhance vaccine efficacy.Sars-cov-2 human infection associated immunity is least probable to be associated with disease enhancement, while the postvaccination immunity can be in association with antibody or T cell disease enhancement.Covid-19 herd immunity is rather difficult to attain in natural infection since it need at least several round of infections to pass in herd a matter which may leave millions of deaths till reaching 50\% herd immunity threshold due to marked heterogeneity of the herd member responses. The most likely speculated durability of post infection immunity was ranging between three, six ,eight up to 12 months. Efficacy of post infection immune response on reinfection remained to be more elucidated .

\section{References}

Addetetia,A. , Crawford, C.A.D., Dingens ,A.,Zhu ,H. ,Roychoudhury P.et al.(2020).Neutralizing antibodies correlate with protection from sars-ciov-2 in human during a fishery vessel outbreak .J.Clin.Microbiol.Doi.101128/JCMo217-2.

Altmann ,D.M.(2020).Adaptive immunity to sars-cov-2.A review.Oxford. Open. Immunol.1(1) :1qaaoo3.dio.10.1093/iqaa003.

Bastard,P.,Rosen,L.B.,Zhang,Q.Michailidis,E.,Hoffmann,H.H. et al.(2020).Autoantibodies against typeI IFNs in patients with life threatening covid-19.Science.10.1126/science.abd4585.

Branswell,H.(2020).Four scenarios on how might develop immunity in covid-19.STAT.

Dmarco,C.(2020).Covid-19 herd immunity: Seven Questions ,answered. M.D. Anderson Centre.

Edridge ,A.W.D.,Kaczorwska,J.,Hoste,A.C.R.,Bakker,M.,Kelin,M.et al.(2020).Seasonal coronavirus protective immunity is short lasting. Nature Medicine.doi.org./10.1038/s41591-0201083-1

Figueiredo-Campos,P.et al.(2020).Sero-prevalence of anti-sars-cov-2 in c ovid-19 patients and healthy volunteers up to six months post disease onset. Europ.J.Immunol .Oct.21.2020. Doi. org./10.1002/ej2020.004890

Fontanet,A . \&Cauchemez ,S.(2020).Herd immunity: where are we.Nature Review Immunol. 20:283-584.

Illarionov,A.\&Pivovarova, .(2020).Two super- types of Coronovirus :East Asian and European. Cato Press. Cato At Liberty.

Jesenak,M.,Brndiarova ,M.,Urbancikkova,I.,Rennoverova,Z.,Vojtkova ,J.et al.(2020).Immune Parameters and covid-19 infection-associted with clinical severity and disease prognosis .Front. Cell.Infect.Microbiol.2020.Jun30.doi.:10.3389/fcimb.202000364.

Kirkcaldy ,R.D.,King,B.A.,Brooks,J.T.(2020).Covid-19 and post-infection immunity: limited evidence,many remaining questions.Am.Med.Ass.323(22):2245-2246.

LeBert,N.,Tan,A.T.,Kunasegaran,C.Y.L.,Hafezi,M.et.al.(2020).Sars-Cov-2 specific T cells in cases of covid-19 and sars un-infected.Nature.584:457-462.

Lewis ,N.(2020).Herd immunity to covid-19 and the pre-existing immune responses. Comments .Uncategorized .Bookmark. The Permalink.

Liu,L.wang,P.,Nair,M.S.Yu,J.,Rapp,M. et al.(2020).Potent antibodies directed to multiple epitopes on sars-cov-2 spike,Nature.Jun.2020.doi.org/10.1038/s41586=020-2571-7.

15-Marias,B.J.\&Sorrell,T.C.(2020).Pathways to covid-19 community protection .Int.J.Infect .Dis.96:496-499.

Mateus,J.,Gerfoni,A.Tarke,A.,Sidney,J.Ramis,S.I.et al.(2020).Selective and cross-reactive Sars-cov-2 T cell epitopes in un-exposed humans.Science.370:89-94.

McFadyen,J.D.,Stevens,H.,Peter,K.(2020).Emergence threats(micro)thrombi in covid-19 and its therapeutic implications. Circulation Research.127(4):571-587.

Ng,K.W.,Faulkner,N.,Cornish,G.H.,Rosa,A.Harvey,R.et al.(2020).Pre-existing de novo humoral immunity to sars-cov-2 in humans.BioRixv.doi.org./101101/2020.05.14.095414.

Omer,S.B.,Vildirim,I,Forman,H.P.(2020).Herd immunity and implication of sars-cov-2 control.J.A.M.A.Oct.19.2020.

Papachristodoulou,F.Kakoutltis,L.Parperis,K.Panos,G.(2020).Long term and herd immunity against sars-c0v2.implication for current and past knowledge .Pathog.Dis. 78(3)ftaa025.

Parrot,T.,Gorin,J-B.,Bonzetta,A.,Maleki,K.T.,Kammann,T.et al.(2020).MAIT cell activation and dynemics associated with covid-19 disease severity.Sci.Immunol.101126/science.abd.4585.

Ragab,D.,SalalEldin,H.,Taemah,M.,Khatab,R.Salem,R.(2020).Covid-19 cytokine storm:What we know so far.Front.Immunol.16,Jun.2020.

Sanchez,E.(2020).Covid-19 science: understanding the basics of herd immunity.Editor@ heart.org.Popular 
article.

Sette A.\&Crotty,S.(2020).Pre-existing immunity to sars-cov-2:The known and unknowns .Comments .Nature Immunolgy.20:457-458.

Sherina,N.et.al.(2020).Persistence of Sars-cov-2 epecific B and T cell responses in convalescent covid-19 patients 6-8 months following infection .BioRixv.doi.org /10.1101/2020.Pri-print not certified by peer review.

Shnawa,I.M.S.(2014).Individual variations and human herd immunity.J.N.S.R.4(8):31-38.

Speiser,D.E.\& Bacmann,M.F.(2020).Mechanism of vaccination and immunity. Vaccines .8.404.Doi.:103390./vaccines.8030404.

Stephens,D.S.\&McElrath,M.J.(2020).Covid-19 and the path to immunity.Opinion .J.A.M.A Sept.11.2020.

Sudre C.H.,Lee,K.A.,Lochainn,M.N.,Varsavisky,T.,Marray,B.,et al.(2020) .Symptom clusters in covid-19:A potential clinical prediction tool from the covid symposium .MedRixv. doi,org $/ 10$. 1101/2020,6.12.20129058.

Vabret ,N,, Britton, G.C,, Gruber, C. ,Hegde, . ,Kim ,J. et al.(2020).Immunology of Covid-19:Current state of Science .Immunity 52:910-941.

Wajnberg, A., Amanat, F. , Firpo, A. , Altman, D.R., Baily, M.J.et al.(2020).Sars-cov-2 infection induces robust neutralizind antibody responses stable at least three months .MedRxiv .preprint not certified by peer review.doi.org101101/2020/7/14.2051126. 